\title{
Las defensorías de las audiencias de los medios de comunicación en El Salvador
}

\section{The Ombudsman of mass media audiences in El Salvador}

ISSN 2071-8748

E-ISSN 2218-3345

(c) $(9)$

URI: http://hdl.handle.net/11298/960

DOI: https://doi.org/10.5377/entorno.v0i67.7503
Camila Calles Minero Universidad Tecnológica de El Salador Camila.calles@utec.ed.sv ORCID: 0000-0002-4936-322X

Leida Monterroza Matute Universidad Autónoma de Santa Ana Monterroza.leida@gmail.com ORCID: 0000-0002-6922-143X

Recibido: 16 de octubre 2018 Aprobado: 12 de mayo 2019

\section{Resumen}

Este artículo muestra los resultados de una investigación cualitativa sobre la factibilidad y aceptación de las defensorías de las audiencias en El Salvador, como un mecanismo para fortalecer el derecho a la información de la población salvadoreña, y con ello, mejorar la calidad de los contenidos que se ofrecen. Se realizaron entrevistas en profundidad y grupos focales con periodistas y líderes de opinión. Se buscó la opinión de los directores y dueños de medios, pero no se obtuvo ninguna respuesta. Los resultados fueron analizados en ATLAS.ti. La conclusión principal es que El Salvador no está listo para la creación de defensorías de las audiencias, pese a que se tiene claridad en que los contenidos mediáticos no son de la mejor calidad y no responden a los intereses de la población.

\section{Palabras clave}

Defensor del pueblo, medios de comunicación de masas, libertad de palabra, derecho a la información, audiencia (medios de comunicación de masas).

\section{Abstract}

This article shows the results of a qualitative investigation into the feasibility and acceptance of an Ombudsman for audiences in El Salvador as a mechanism to strengthen the right to information of the Salvadoran population, and thereby improve the quality of the content offered. In-depth interviews and focus groups with journalists and opinion leaders were conducted. The opinion of the media owners and directors was sought, but no response was obtained. The results were analyzed using ATLAS.ti. The main conclusion is that El Salvador is not ready for the creation of an Ombudsman, although it is clear that the media content is not of the best quality and does not respond to the interests of the population.

\section{Keywords}

Ombudsman, mass media, freedom of speech, right to information, audience (mass media). 


\section{Introducción}

El objetivo principal de la investigación fue determinar la factibilidad y aceptación del ombudsman de las audiencias de contenidos informativos en grupos sociales y medios de comunicación en El Salvador. Para ello se establecieron como objetivos específicos conocer la percepción de los grupos sociales sobre el derecho a la información y la libertad de prensa, y, acerca del ombudsman, identificar su aceptación en grupos sociales, establecer la factibilidad de su utilización e indagar su perfil idóneo.

Cuando se habla de las defensorías de las audiencias de los medios de comunicación, inevitablemente surge el fantasma de la censura, del control, de la ausencia de libertad; sin embargo, cuando se quiere hacer referencia al ejercicio corrector del periodismo, desde parámetros técnicos y éticos, se convierte en una figura indispensable. Existen múltiples ejemplos en países de América Latina, como Colombia y México, los más cercanos a El Salvador con defensores de audiencias, que dan cátedra sobre la presencia de esta figura; y basados en esa experiencia en El Salvador se debe abrir el camino para la discusión de crear o no un ombudsman. Esta investigación pretendió iniciar esa discusión; se muestra el conocimiento que hay del tema, así como la factibilidad de su creación en el corazón de las redacciones de los medios de comunicación salvadoreños.

Hasta el 2018, solamente un medio de comunicación salvadoreño ha dispuesto oficializar la figura que vela por los derechos de las audiencias. El 1 de junio de ese año, el periódico digital ElFaro .net abrió la primera defensoría del lector en El Salvador. La chilena Mónica González Mujica asumió su cargo como Defensora del Lector de El Faro.

Este artículo es producto de una investigación de carácter cualitativo, cuyo objetivo principal fue analizar la percepción sobre el derecho a la información y la libertad de expresión, asociados con la figura del ombudsman de las audiencias de los medios de comunicación, así como establecer la factibilidad y aceptación de este defensor de las audiencias en los medios de comunicación salvadoreños.

Se parte de la premisa de que la figura del ombudsman de las audiencias es relevante no solo por su labor como garante de la calidad del trabajo periodístico, sino también porque representa un mecanismo que garantiza la participación de la ciudadanía en la agenda noticiosa y en el resguardo de los derechos como receptores de información.

Los resultados de esta investigación pretenden ser insumo de discusión acerca de la necesidad de que los medios salvadoreños cuenten con una figura garante de los derechos de sus propias audiencias. Además, se plantean los principales obstáculos que impiden que se implementen figuras como el ombudsman, así como también se resumen las principales características que debería tener este personaje, y su relación con la realidad de los medios salvadoreños.

La base principal de la investigación la constituyen las voces de especialistas en el tema, periodistas, líderes sociales, docentes universitarios, estudiantes del área de comunicaciones a quienes se abordaron mediante entrevistas y grupos focales. Estos insumos construyen el perfil del defensor de las audiencias para El Salvador.

Restrepo (2016) explica que los defensores de las audiencias derivan su nombre del ombudsman, un funcionario sueco que velaba por la limpieza de las calles y las chimeneas. Se relacionan con el intermediario que el rey Carlos XII creó en Suecia, en 1713, para fortalecer su relación con el pueblo; ese intermediario se convirtió en 1916 en un Consejo de Prensa que recibía las quejas de la población sueca contra cualquiera de los periódicos del reino. El defensor individual solo apareció en 1967, ante el fracaso del Consejo de Prensa; y en el mismo año, dos periódicos de Lousville, en Kentucky, nombraron a John Herchenroeder como el primer ombudsman en Estados Unidos. Pero, en esa ocasión no fue solamente para recibir quejas. Los directores de The New Year Joumal y del Courrier Journal se estaban preguntando: "¿Qué es lo que anda mal en la prensa?"; y a Herchenroeder le correspondía responderlo (Restrepo, 2016).

El ombudsman sueco nace como un representante de los derechos de los ciudadanos frente a la administración pública. Con el paso del tiempo, se ha adoptado en distintos ámbitos no gubernamentales, entre ellos la prensa. Este tipo de papel se origina en los diarios como parte de sistemas de autorregulación (al igual que los códigos éticos, los manuales de estilo o los estatutos de redacción) mediante los cuales algunos medios asumen públicamente un compromiso de respeto a principios éticos y de diálogo con sus destinatarios. A fin de cuentas, se trata de un reconocimiento del derecho a la comunicación, el cual ampara y protege no solo a 
quienes ocupan el lugar de productores o emisores, sino también a quienes reciben esos contenidos. (Pauwels, 2014)

La figura del ombudsman no solo existe en la prensa escrita, también emisoras de radio y de televisión han creado sus defensores de las audiencias. McKenna (1993) establece que, fue la cadena televisiva CBS de Estados Unidos una de las primeras en construir esta figura en un medio audiovisual en la década de los ochenta. Actualmente no se puede precisar el número exacto de defensores de las audiencias que existe en el mundo. Hasta 2017, la Organization of News Ombudsmen (ONO, 2018) estimaba un centenar. Esta figura suele aparecer y desaparecer con cierta periodicidad en las redacciones de los medios de comunicación.

Las defensorías de las audiencias de los medios de comunicación permiten a los ciudadanos encontrar un vínculo con los medios de comunicación que les haga valer el derecho a la información. Sin embargo, en países como El Salvador es una figura que no existía hasta 2018, cuando el periódico digital ElFaro .net habilitó la primera defensoría del lector.

Ante la ausencia de las defensorías, los medios de comunicación privados y estatales producen noticias que las audiencias consumen sin tener la garantía de que las salas de redacción atenderán quejas, comentarios 0 interrogantes, ante la insatisfacción por el tratamiento que dan a la producción de contenidos noticiosos.

En El Salvador existe la Ley Especial del Ejercicio del Derecho de Rectificación o Respuesta, para que toda persona que se considere perjudicada por una información o noticia que no corresponda a hechos ciertos pida inserción gratuita de la correspondiente rectificación o respuesta. Se desconoce la utilización de este instrumento legal y la respuesta que puedan haber dado los medios de comunicación salvadoreños.

En ese sentido, el papel del ombudsman va más lejos, pues se convierte en el canal adecuado para dar a conocer el proceso que un periodista siguió para publicar hechos, y contribuir a la transparencia de los medios de comunicación. Pero además sirve de nexo entre la población y los medios de comunicación, llevando a estos últimos las principales necesidades de los consumidores de los medios y abogando por el respeto a los derechos humanos y el libre ejercicio del periodismo.
Pero, además, conocer y entender esta figura es importante para dar insumos para la consecución de los Objetivos para el Desarrollo Sostenible, en cuyas metas 16.6 y 16.10 se espera llegar a crear a todos los niveles instituciones eficaces y transparentes que rindan cuentas y garantizar el acceso público a la información y proteger las libertades fundamentales, de conformidad con las leyes nacionales y los acuerdos internacionales (Naciones Unidas-Cepal, 2018).

En América Latina, la figura del defensor de la audiencia ha caminado lenta: Brasil fue el pionero en ponerlo en práctica a finales de los años ochenta; 10 años después lo replicó Colombia; sin embargo, casi tres décadas después de esta primera iniciativa brasileña el ombudsman de las audiencias únicamente está presente en ocho países latinoamericanos (ONO, 2018).

La presencia de una defensoría de las audiencias de los medios de comunicación es tema retomado desde la esfera mundial. Desde 1989, en la 25. ${ }^{\text {a }}$ reunión de la Conferencia General de la Organización de las Naciones Unidas para la Educación, la Ciencia y la Cultura (Unesco), en la que se aprobó la Nueva estrategia de Comunicación, las Naciones Unidas aboga por "la libre circulación de las ideas por medio de la palabra y la imagen" (Unesco, 2014). A partir de la Declaración de Windhoek, un documento seminal, adoptado en 1991 y aprobado por sus Estados Miembros, la Unesco entiende que la libertad de prensa designa las condiciones que requieren la libertad, el pluralismo y la independencia de los medios, además de la seguridad de los periodistas (Unesco, 2014).

De igual forma, el artículo 19 de la Declaración Universal de Derechos Humanos establece que "todo individuo tiene derecho a la libertad de opinión y de expresión; este derecho incluye el de no ser molestado a causa de sus opiniones, el de investigar y recibir informaciones y opiniones, y el de difundirlas, sin limitación de fronteras, por cualquier medio de expresión" (Naciones Unidas, 2015).

Pese a esas disposiciones internacionales, en El Salvador hasta el 2018 no existieron iniciativas de la creación de figuras como el ombudsman, la cual podrá significar un paso hacia la garantía de la libertad de expresión, el respeto a los derechos de las audiencias y el libre ejercicio periodístico. 
En cuanto a la legislación, que podría amparar la figura de las defensorías de las audiencias de los medios de comunicación, actualmente no hay, en El Salvador, una ley específica para medios de comunicación; sin embargo, se conoce de dos iniciativas de ley presentadas a la Asamblea Legislativa, que todavía permanecen en estudio para su aprobación: el Proyecto de Ley de Radiodifusión Comunitaria y el Proyecto de Ley de Medios de Comunicación Públicos, que son parte de la agenda de trabajo de la Comisión de Legislación y Puntos Constitucionales. El primero fue presentado en julio de 2013 por la Asociación de Periodistas Salvadoreños (Apes), la Asociación de Radios y Programas Participativos de El Salvador, la Fundación de Estudios para la Aplicación del Derecho, la Universidad Centroamericana José Simeón Cañas y otras 50 organizaciones sociales, académicas y de medios alternativos; y el segundo fue presentado dos meses después, en septiembre del mismo año. Además de esas iniciativas de ley presentadas a la Asamblea, la Apes se encuentra formulando la Ley de Protección, Previsión y Seguridad Social del Periodista, la cual aún está en el período de consulta y elaboración.

A pesar de este vacío de ley, los medios salvadoreños se rigen por una serie de normas y tratados tanto nacionales como internacionales, entre los que se encuentran la Constitución de la República (artículo 6), Declaración Universal de los Derechos Humanos (Artículo 19), Ley Especial del Ejercicio del Derecho de Rectificación o Respuesta (Artículo 2), Ley de Acceso a la Información Pública: Derecho de Acceso a la Información Pública (Artículo 2), Convención Americana sobre Derechos Humanos (Artículo 14) y Ley de Protección Integral de la Niñez y Adolescencia (Artículo 97).

Pilares legales existen para dar soporte a la creación de defensorías de las audiencias de los medios de comunicación, por ello esta investigación muestra la factibilidad desde la opinión y conocimiento de periodistas, directores y dueños de medios de comunicación y líderes de opinión.

\section{Metodología}

Esta investigación se realizó sobre la base de los estudios cualitativos. Para Hernández, Fernández y Baptista (2014), los estudios cualitativos son abiertos, expansivos, no direccionados en su inicio, fundamentados en la experiencia e intuición. Estos estudios se aplican a un número pequeño de casos para lograr el entendimiento del fenómeno en la mayor parte de sus dimensiones. Los estudios cualitativos son orientados a aprender de experiencias y puntos de vista de los individuos, valorar procesos y generar teoría fundamentada en las perspectivas de los participantes. Por ello se realizó un grupo focal con periodistas (de los medios de comunicación analizados) para conocer su experiencia y ampliar el análisis de los datos numéricos. Estos autores señalan, además, que, en los estudios cualitativos, al no interesar tanto la posibilidad de generalizar los resultados, las muestras no probabilísticas o dirigidas son de gran valor, pues logran, si se procede cuidadosamente y con una profunda inmersión en el campo de estudio, obtener los casos que interesan al equipo investigador y que lleguen a ofrecer una gran riqueza para la recolección y el análisis de los datos.

Por su parte, Salgado (2007) cita a Jiménez-Domínguez (2000) al reflexionar sobre las características de la investigación cualitativa, afirmando que "la investigación cualitativa puede ser vista como el intento de obtener una comprensión profunda de los significados y definiciones de la situación tal como nos la presentan las personas, más que la producción de una medida cuantitativa de sus características o conducta" (p. 1).

Acorde con su profundidad, fue un estudio exploratorio, que abordó un tema poco conocido en el ámbito salvadoreño; y se orientó a explicar las variables que intervienen en aquel. Por el problema estudiado, la investigación se definió como evaluativa, ya que investigará la factibilidad y aceptación del ombudsman en los medios de comunicación.

La recolección de la información se realizó en dos etapas, abordadas en diferente momento y por distinta técnica. La primera consistía en realizar entrevistas en profundidad, para lo cual se diseñaron dos guías con preguntas abiertas: una estaba orientada a jefes de prensa, directores o propietarios de medios de comunicación y la otra a consumidores de información.

Para el caso de los grupos focales, estos se realizaron basados en los resultados de las entrevistas; y por tanto se llevaron a cabo al finalizar el análisis preliminar de estas. De igual forma que en la etapa anterior, a la hora de diseñar el instrumento de recolección de datos se estableció diferencia entre las personas del mundo de las comunicaciones y los consumidores de la información, por lo que se diseñaron también dos guías con preguntas abiertas. 
Con la intención de orientar la búsqueda de información, mediante entrevistas y grupos focales, se establecieron cinco categorías de análisis, respondiendo a los objetivos de la investigación, que a su vez fueron desglosados en subcategorías e indicadores. Las categorías principales utilizadas en esta investigación fueron: 1. Concepto de ombudsman de las audiencias de los contenidos informativos, 2. Condiciones financieras para que exista el ombudsman, 3. Apertura y disposición de los medios de comunicación social, 4. Condiciones legales para la existencia del ombudsman, Conocimiento sobre el tema, 5. Características del ombudsman de las audiencias de los contenidos informativos, 6. Trabajo de los medios de comunicación, 7. Libertad de expresión y 8. Interés informativo de las audiencias.

Se realizó un muestreo dirigido, por lo que la muestra estuvo conformada por participantes considerados idóneos para el estudio, quienes cumplieron con los siguientes criterios: Personas con experiencia en el tema de la libertad de expresión,Políticospartidarios, Líderesdeopinión,Periodistas y comunicadores que trabajen en medios de comunicación,
Periodistas y comunicadores que no trabajen en medios de comunicación, Directores o jefes de prensa, Dueños de medios de comunicación, Docentes de Comunicaciones o Periodismo, Estudiantes de Comunicaciones o Periodismo, Deportistas, Empresarios (grandes, medianos o pequeños), Abogados, Líderes religiosos.

Se obtuvo un total de 29 entrevistas y se realizaron dos grupos focales en los que participaron 17 personas. Las entrevistas fueron realizadas en el período comprendido entre julio y agosto de 2017, mientras que los grupos focales se realizaron en los meses de octubre y noviembre. Ambos resultados fueron analizados en el software cualitativo Atlas.ti para establecer relaciones semánticas entre las categorías.

\section{Análisis de los resultados}

En total se obtuvieron 406 citas de las entrevistas en profundidad realizadas. En la tabla 1 se puede ver su distribución de acuerdo con las categorías que se inspeccionaron.

Tabla 1. Distribución del número de citas respecto a las categorías analizadas

\begin{tabular}{|l|c|}
\hline \multicolumn{1}{|c|}{ Categorías } & n. $^{0}$ de citas \\
\hline Apertura y disposición de los medios de comunicación & 68 \\
\hline Características del ombudsman & 47 \\
\hline Concepto de ombudsman & 29 \\
\hline Condiciones financieras & 36 \\
\hline Condiciones legales & 22 \\
\hline Conocimiento del tema & 34 \\
\hline Interés de las audiencias & 33 \\
\hline Libertad de expresión & 64 \\
\hline Trabajo de los medios de comunicación & 73 \\
\hline Total & 406 \\
\hline
\end{tabular}

Fuente: tabla elaborada por las investigadoras a partir del análisis de las entrevistas en Atlas.ti. 
Para el caso de las entrevistas en profundidad, las relaciones semánticas más fuertes establecidas por la cantidad de citas en cada categoría y su relación con otras categorías se concentraron en Libertad de expresión, Apertura y disposición y características del ombudsman.

A continuación, en la ilustración 1 se muestran las relaciones de estas categorías (tomando en cuenta únicamente las tres relaciones más fuertes).

Ilustración 1. Relaciones semánticas de la categoría: Libertad de expresión

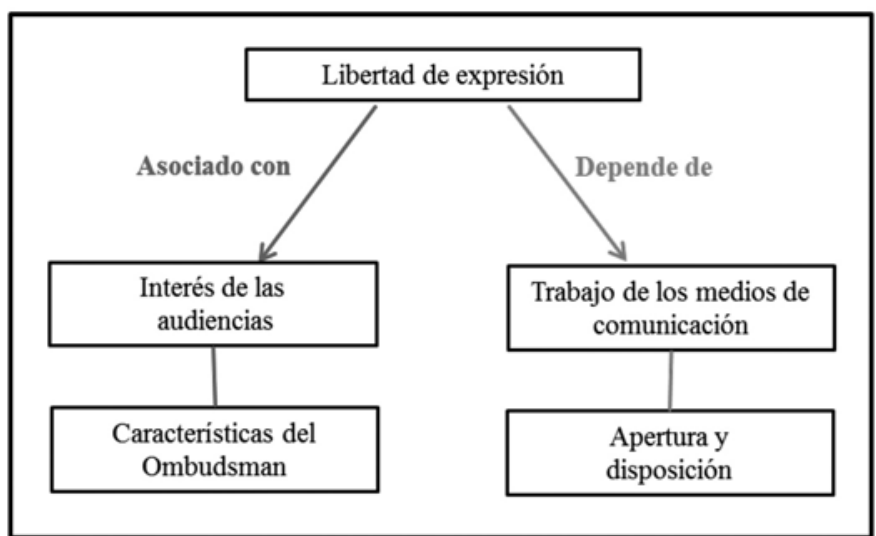

Fuente: ilustración elaborada a partir datos generados en Atlas.ti.

En la ilustración 1 se puede ver que, para los entrevistados, la libertad de expresión está asociada con el interés que tengan las audiencias de hacer valer tal derecho, pero también por el interés que pueda existir dentro de los medios de comunicación por escuchar a la población. Además, para que haya libertad de expresión se deben establecer características específicas a la figura del ombudsman, puesto que, según los entrevistados, dicha figura abonaría al respeto y cumplimiento de la libertad de expresión.

Los entrevistados creen que el respeto a la libertad de expresión depende en gran medida del trabajo y la dinámica propia de los medios de comunicación. Pero sobre todo de la apertura que estos tengan por que existan mecanismos externos al medio que coadyuven a ello.

En cuanto a la Apertura y disposición (ilustración 2), los entrevistados consideran que, en la medida que los medios de comunicación estén dispuestos a tomar en cuenta el interés de las audiencias, habrá más apertura para aceptar o no medidas de control interno y externo de sus contenidos. 
Ilustración 2. Relaciones semánticas de la categoría: apertura y disposición

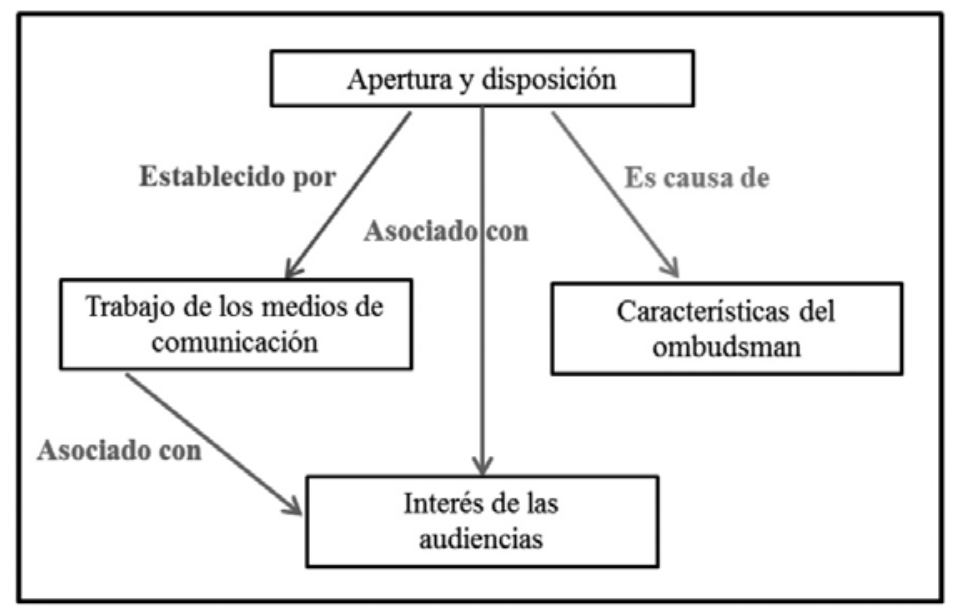

Fuente: ilustración elaborada a partir datos generados en Atlas Ti.

De igual manera consideran que la apertura a, y disposición de, mecanismos de control está supeditada al trabajo de los medios de comunicación, en cuanto a que su dinámica de búsqueda de información y soporte económico no se vean afectados, considerando estos mecanismos de control como formas de censura.

Ahora bien, este trabajo de los medios de comunicación debe, según los entrevistados, estar íntimamente asociado con el interés de las audiencias, en cuanto a que la dinámica propia de la difusión de información se debe enfocar en las necesidades informativas de las audiencias, más que en el interés propio de cada medio de comunicación.

En cuanto a la categoría Características del ombudsman, está determinada por el conocimiento que tienen los entrevistados de dicha figura, además, de las condiciones legales y económicas de El Salvador, del trabajo, y de la apertura y la disposición de los medios de comunicación. En ese sentido, las características que debe tener el ombudsman de las audiencias de los medios de comunicación, según los entrevistados, dependen en gran medida del conocimiento sobre el tema, pues algunos le confieren atributos afines a la profesión de abogado, mientras que otros le confieren características propias de periodistas y comunicadores (63 citas relacionadas).

Esta investigación establece, además, que el conocimiento del tema es reducido en los distintos sectores sociales. Quienes mejor conocimiento tienen son los periodistas y profesionales relacionados con las comunicaciones, mientras que otros profesionales entrevistados nunca habían escuchado del concepto del ombudsman de las audiencias. Esto indica que la sociedad en su conjunto desconoce de la existencia de figuras que contribuirían a la libertad de expresión en El Salvador.

Los grupos focales, al igual que las entrevistas, fueron analizados mediante la relación de las categorías semánticas, obteniéndose un total de 43 citas, cuya distribución se detalla en la siguiente tabla. 
Tabla 2. Distribución del número de citas respecto a las categorías analizadas

\begin{tabular}{|l|c|}
\hline Categorías & n. ${ }^{\circ}$ de citas \\
\hline Características del ombudsman & 7 \\
\hline Trabajo de los medios de comunicación & 7 \\
\hline Apertura y disposición de los medios de comunicación & 6 \\
\hline Condiciones legales & 5 \\
\hline Conocimiento sobre el tema & 5 \\
\hline Concepto ombudsman & 5 \\
\hline Condiciones financieras & 4 \\
\hline Libertad de expresión & 4 \\
\hline Total & 43 \\
\hline
\end{tabular}

Fuente: tabla elaborada por las investigadoras a partir del análisis de los grupos focales en Atlas.ti.

Con base en la cantidad de citas, se observa una relación semántica más robusta en las categorías Características del ombudsman, Trabajo de los medios de comunicación y Apertura y disposición de los medios de comunicación.

La primera categoría, Características del ombudsman, está estrechamente relacionada con el concepto del ombudsman de las audiencias, así como también con el conocimiento sobre el tema y con la libertad de expresión, de tal manera que, para saber qué características debe tener esta figura para poder desempeñar su cargo en el ambiente salvadoreño, se debe tener claridad en primer lugar de cuál es el significado del ombudsman de las audiencias, cuáles son sus atribuciones y qué papel ha desempeñado en otros países.

Además, las características del ombudsman de las audiencias están asociadas con el conocimiento del tema, en tanto que dichas características deben corresponder al ambiente que se vive en los medios de comunicación salvadoreños; qué tipo de medios hay en el país, cuáles son los criterios que prevalecen a la hora de diseñar la agenda informativa, entre otros, razón por la cual, según los participantes de los grupos focales, una de las características de la persona que asuma la función de ombudsman de las audiencias es que "no sea amigos de los medios", además de que no esté ligado a ningún partido político.
La segunda categoría con mayor peso, por su relación, es El trabajo de los medios, que se vincula estrechamente con las condiciones financieras, el concepto del ombudsman y la libertad de expresión. El trabajo de los medios de comunicación en El Salvador es causa de sus propias condiciones financieras, ya que son corporaciones dirigidas por empresarios, y, por tanto, sus contenidos y agenda periodística estarán subordinados a razones económicas y no periodísticas. La opinión generalizada en cuanto al trabajo de los medios fue que no responde a las necesidades de las audiencias, y que esto se debe a la estructura de los medios, partiendo de que son empresas dirigidas por grupos de poder $y$, por tanto, sus contenidos y posturas irán siempre hacia generar mayores ganancias.

También existe una relación semántica opuesta entre el trabajo de los medios de comunicación con el concepto del ombudsman, cuya función es velar por el correcto funcionamiento ético de los medio de comunicación, además de vigilar porque el trabajo de los medios de comunicación sea imparcial, tenga equilibrio y buen gusto (Herrera, 2008), sin embargo los medios de comunicación salvadoreños carecen de códigos de ética propios, únicamente se cuenta con el que elaboró la Apes, el cual no es de estricto cumplimiento. 
Existe, además, una relación contradictoria entre el trabajo de los medios de comunicación y las características del ombudsman, pues la apreciación es que el periodismo ha perdido su esencia educativa; ya no se investiga, no se profundiza en la noticias y los intereses de las audiencias no son los relevantes en la agenda noticiosa; por ello una de las características sugeridas es que el ombudsman sea una persona que vele por los intereses tanto del periodista como de los lectores y hasta de los mismos dueños.

Finalmente, la tercera categoría que tiene mayor relación con las otras es Apertura y disposición de los medios, la cual se vincula con las condiciones financieras; es consecuencia del trabajo de los medios, y opuesta, o está en contradicción con, al concepto y las características del ombudsman.

La apertura y disposición de los medios se refiere a qué tanta disponibilidad y aceptación existe en los medios de comunicación salvadoreños, para que la figura del ombudsman de las audiencias pueda ser establecida. Es por eso que esta categoría se contradice con el concepto y las características del ombudsman de las audiencias, pues la mayoría de los medios salvadoreños hasta el momento no cuentan con manuales de estilo ni códigos de ética, pero sobre todo han rechazado cualquier iniciativa que los lleve a mejorar sus contenidos en función de las necesidades de las audiencias. También, la apertura y disposición de los medios está asociado con el trabajo de ellos mismos; y también es causa de las condiciones financieras, pues, según los participantes, El Salvador se caracteriza por tener un periodismo poco serio, en donde la agenda noticiosa debe responder a las necesidades económicas, por tanto, el ombudsman de las audiencias no tendría aceptación.

Cuando se habla concretamente del respeto al derecho a la información por parte de los medios de comunicación, también se afirma que se pone en práctica dicha libertad porque hay diversas formas de expresar el pensamiento, además de una amplia gama de medios informativos convencionales y no convencionales (prensa escrita, radio, televisión, blogs, redes sociales, periódicos digitales, etc.); y la gente puede tener acceso a ellos según sus necesidades, gustos o preferencias.

La opinión general de los entrevistados es que la información brindada a la ciudadanía está "polarizada", y destacan los contenidos que responden a los intereses particulares -políticos y comerciales- de dichos medios de comunicación, que los impulsan a orientar el tipo de información a sus necesidades económicas o a sus inclinaciones ideológicas.

En El Salvador existen los mecanismos legales para garantizar el respeto al derecho a la información y la libertad de expresión; sobre este tema, la percepción de los entrevistados fue que la libertad de expresión y de información, así como del derecho a respuesta, no son accesibles a la mayoría de la población debido no solo a la poca difusión y el desinterés de los medios de darle espacio a todos los sectores sociales para expresarse, sino también por el desinterés de la población para exigir su derecho a estar informado, la poca educación y cultura de reclamo, la falta de conocimiento y la incapacidad de la población de ser crítica ante la realidad que le están ofreciendo los medios de comunicación.

En cuanto a los contenidos informativos, de igual manera que en lo referente a la libertad de expresión y derecho a la información, la opinión fue que los diferentes medios de comunicación del país no están ofreciendo una "agenda de nación adecuada", es decir, una agenda que responda a los intereses de país, por el contrario, los contenidos que difunden responden a sus intereses particulares, económicos y políticos.

Por otra parte, para comprender la selección de los temas de la agenda periodística, se debe tomar en cuenta que los medios de comunicación son en primer lugar empresas, por lo que su fin es obtener mayores ventas, sobre todo en lo que respecta a publicidad, por lo que la elección de dichos temas estará condicionada también a aquello que más vende: noticias sobre violencia -en ocasiones con enfoque amarillista-, dibujos animados, novelas y deporte, temas orientados sobre todo a entretener a la población, obviando aquellos contenidos con enfoque educativo y cultural.

Algunos entrevistados consideran que los medios sí están proporcionando la información que la población necesita. El matiz está en que es la misma población la que debe seleccionar, según sus intereses y gustos, qué medio o medios consultar; dado que vivimos en un sistema democrático, con una amplia gama de medios formales e incluso informarles (todos aquellos blogs, redes sociales o algunos periódicos en línea de reciente formación).

Esta tarea de seleccionar los medios de comunicación conforme con "mis intereses" implica que la audiencia 
tenga cierto grado de educación, disciplina y el claro conocimiento de cuál es la información que realmente le servirá para lograr enterarse de la realidad, además de que es necesario consultar diversos medios de comunicación antes de tomar una postura o formarse la opinión sobre algún tema relevante.

La mayoría de los medios de comunicación están dando prioridad al formato noticia; en la agenda prima lo "inmediato o del momento", lo obtenido en la conferencia de prensa, en la fuente primaria, pero dejan de lado el periodismo investigativo y están reduciendo la información a una sola fuente, lo cual en algunos casos puede restar veracidad a la información.

Esta medida, considerada "comercial", va creando vacíos en la calidad de la información que se está brindando a la población, además de restar credibilidad al medio. A pesar de estas limitantes, los medios de comunicación se inclinan por esta práctica, ya que reduce costos y tiempo porque el periodista no dedica muchas horas para obtener y redactar la noticia; "es lo que por el momento vende", y la mayoría de la población busca simplemente informarse sin profundizar en la temática.

Por otra parte, los entrevistados dijeron que los contenidos informativos que están ofreciendo los medios de comunicación se enfocan únicamente en destacar un aspecto de la sociedad: la inseguridad y violencia actual que se está viviendo en El Salvador, que, si bien es considerado uno de los temas importantes por abordar en la agenda noticiosa, no debe ser lo que más se destaque. Sin embargo, como se señaló anteriormente, la lógica comercial es la que prevalece en los medios, por lo tanto, sus contenidos van enfocados a ofrecer "lo que se vende", "lo que responde al interés del público y no al interés medio, es decir, el interés de la nación".

Es importante también señalar la percepción de que los medios están dando un tratamiento amarillista 0 sensacionalista a las notas, ya que constantemente se percibe, principalmente en aquellos medios visuales (los impresos y los televisivos), que destacan imágenes consideradas "fuertes o poco apropiadas de personas asesinadas, e incluso videos de ejecuciones", sin tomar en cuenta a la audiencia, además de que no aportan información relevante a la noticia.
En cuanto a los contenidos de los medios de comunicación, "hay un déficit", como se mencionó anteriormente, porque se han dedicado a presentar algunos temas de la realidad nacional, o de "agenda nacional", como la delincuencia y la política, pero están dando menos cobertura a otros temas de igual importancia, como los "que afectan el diario vivir", por ejemplo, los derechos ciudadanos, la educación, la cultura, la economía y el medio ambiente.

La participación activa de las audiencias en los medios de comunicación es parte de la "democratización de las comunicaciones"; sin embargo, sobre este aspecto se opinó que las audiencias permanecen pasivas frente a los retos de valorar y cuestionar la información que el medio de comunicación les está proporcionando, tampoco están formados con conciencia de su realidad ni en la lectura crítica de lo que se les está brindando en los medios.

Por otro lado, tampoco los diferentes sectores de la población se interesan en hacer uso de los espacios que los medios les han habilitado, y presionar para que los contenidos respondan al interés público y no al particular de los dueños de las grandes empresas mediáticas.

De acuerdo con las personas entrevistadas, si bien la mayoría de los medios de comunicación habilitan mecanismos que le permite tener un acercamiento con sus audiencias: Ilamadas en vivo, correo electrónico, espacios en las redes sociales (Facebook, Twitter, Snapchat e Instagram), la población está haciendo muy poco uso de estos mecanismos, ya sea por desconocimiento o por falta de cultura; de igual manera, el editor tiene la libertad de ignorar, borrar o responder a los comentarios, sugerencias o propuestas de la población usuaria, tomando en cuenta criterios como pertinencia, veracidad o conveniencia de dichos comentarios.

En cuanto al conocimiento del término ombudsman de las audiencias, está reducido a aquellos sectores cuyo trabajo se relaciona directamente con los medios de comunicación (periodistas, jefes de prensa); y también lo conocen aquellas personas que no pertenecen a ningún medio pero que su trabajo implica algún contacto con los medios (oficiales de información, jefes o directores de las unidades de comunicaciones). En estos sectores conocen el concepto gracias al trabajo que realizan los ombudsmen de países como México y Colombia, en los que sí cuentan con esta figura en algunos medios de comunicación. 
Algunos entrevistados que representan sectores no relacionados directamente con los medios de comunicación, basándose en el concepto original del ombudsman - término surgido hace más de un siglo como el defensor del pueblo-, relacionan las funciones propias del ombudsman de las audiencias, con las del procurador de derechos humanos, quien representa también la figura del ombudsman en nuestro país; y una de sus atribuciones es garantizar el respeto a los derechos humanos, entre ellos la libertad de expresión y de información (que son fundamentales). Sin embargo, las funciones del procurador son más amplias y no se limitan al trabajo periodístico o a los medios de comunicación, como lo es en el caso del ombudsman de las audiencias, quien solo tendría incidencia en los medios de comunicación.

Otros, por su parte, consideran que las competencias del ombudsman de las audiencias podrían ser retomadas por la Dirección de Espectáculos Públicos Radio y Televisión porque su función es regular los espectáculos públicos, materiales audiovisuales e impresos con el fin de proteger a la sociedad, particularmente a los menores de edad y a la familia (artículo 1 del Reglamento a la Ley General de Espectáculos Públicos, Materiales Audiovisuales e Impresos). En ese caso, lo que se necesitaría sería actualizar el reglamento de esta institución para que pueda tener funciones que le permitan recibir y gestionar las quejas de las audiencias, entre otras funciones.

En lo que respecta a la aceptación del ombudsman de las audiencias, la opinión general obtenida fue que en el ambiente salvadoreño los medios de comunicación carecen de apertura, madurez y voluntad para invertir en una figura como el defensor de las audiencias. Además, para que esta figura pueda tener cabida en los medios de comunicación salvadoreños hace falta la disposición ideológica de estos, para que le permitan hacer su trabajo tal como es concebido, así como también hace falta flexibilidad de parte de los medios de comunicación para aceptar las críticas a su trabajo. De lo contrario, "la figura del ombudsman se convertiría en un elemento político o decorativo".

Según las entrevistas realizadas, los medios de comunicación, a lo largo de los años, han demostrado ser empresas que defienden su autonomía y no están abiertos a ningún tipo de auditoría o regulación, razón por la cual la figura del ombudsman podría ser vista en las empresas mediáticas como un ente que pretende fiscalizarlos.
En ese sentido, y conforme a las entrevistas y los grupos focales realizados, así como no existe la disponibilidad y apertura de los medios tampoco existen las condiciones financieras ni legales para la implementación de una figura como el ombudsman, pues a nivel general en los medios se apuesta por la autorregulación.

Si bien hay poca apertura de los medios de comunicación y falta de condiciones para el funcionamiento del ombudsman de las audiencias, en El Salvador se considera que dicha figura sí es muy necesaria para fortalecer la libertad de expresión, el derecho a la información y para mejorar la calidad de los contenidos informativos; porque hasta la fecha - a juicio de algunos entrevistados-, sin ningún ente que regule a los medios, la calidad de la información que ofrecen, como se advirtió arriba, seguirá decayendo ya que "carece de profesionalismo y veracidad".

También se debe mencionar que la percepción de los consultados es que la figura del ombudsman beneficiaría no solo a los medios de comunicación, sino también a la audiencia en general porque habría mayor diversidad y transparencia en las noticias, igualmente se garantizarían el respeto a la libertad de expresión, el derecho a la información y el de la rectificación y respuesta.

A pesar de que las personas entrevistadas sí están de acuerdo con la necesidad de que los medios cuenten con una instancia que vele por su correcto funcionamiento ético, algunas de las consultadas expresan su reserva en cuanto a la veracidad que pueda tener esta figura en un ambiente como salvadoreño demasiado "polarizado", en el cual las empresas mediáticas han venido imponiendo su línea de opinión, que responde siempre solo a sus propios intereses.

En cuanto a la factibilidad o no de la utilización de defensorías de las audiencias de los medios de comunicación en El Salvador, la investigación establece que el marco jurídico actual permite el funcionamiento del ombudsman, por lo que no son necesarias nuevas leyes. Además, los entrevistados consideran que no existen impedimentos para su trabajo, puesto que el ombudsman no es un elemento de censura; no afecta la libertad de expresión y el derecho a la información; representa un mecanismo de autorregulación de los medios, y no contradice ninguno de los artículos de la Constitución. 
Sin embargo, cabe señalar que esta figura no se encuentra mencionada en ninguno de mecanismos legales (Constitución de la República, leyes o reglamentos), excepto en el Código de ética para periodistas y profesionales de la comunicación en El Salvador elaborado por la Apes (artículo 46), cuya aplicación no es de carácter obligatorio en los medios de comunicación. En ese sentido, sí es necesario crear un marco regulatorio para su funcionamiento.

Como se ha mencionado, la figura del ombudsman es necesaria para garantizar el correcto funcionamiento ético de los medios de comunicación, sin embargo, su implementación no parece ser sencilla debido a una serie de obstáculos; los principales serían las mismas empresas de comunicación, que, por su naturaleza económica, que en muchos casos también responde a poderes políticos, no han demostrado apertura para mejorar sus contenidos y la calidad de la información que ofrece.

Por otro lado, las audiencias tampoco son lo suficientemente maduras y educadas para presionar por una mejora en la calidad de la información que se les brinda; se muestran reacias ser participantes activos de la información, relegándose ellas mismas a ser consumidoras pasivas de los contenidos que les brindan los medios de comunicación.

Otra de las limitantes que tendría el ombudsman de las audiencias sería el origen de los fondos para mantener su trabajo, porque se debe tomar en cuenta que esta figura en otros países mantiene su autonomía e independencia a pesar de que es pagado por el medio al que audita.

Algunas personas consultadas incluso fueron tajantes en opinar que una figura como el ombudsman de las audiencias, en un ambiente como el salvadoreño, no es viable, debido a condiciones como las que ya se mencionaron: polarización, poca apertura de los medios y falta de financiamiento, entre otras.

El último de los objetivos de la investigación fue plantear un perfil del defensor o defensora de las audiencias de los medios de comunicación para El Salvador. En ese sentido, se establece que, de lograr salvar las barreras que impiden el funcionamiento de un ombudsman en el ambiente salvadoreño, una de sus principales características, según las personas entrevistadas, es que debe ser externo a los medios de comunicación, para que pueda regularlos sin tener ninguna influencia ideológica de parte de los dueños y para que su trabajo sea realizado con profesionalismo.

Otra de las opiniones obtenidas es que la figura del defensor de las audiencias no debería estar a cargo de una sola persona, sino que, para garantizar su autonomía, deberá ser una organización o entidad multidisciplinaria; provenir de las instituciones o tribunales ya existentes o incluso de organizaciones internacionales.

Algunos también consideran que el funcionamiento del ombudsman sería viable si este fuera creado como una propuesta "combinada", es decir, por tratados internacionales, por iniciativa de ley para responder a esos tratados e involucrando también a las audiencias y sectores académicos.

Finalmente, otros consideran que, para garantizar el correcto desempeño de su trabajo, el ombudsman debería surgir por iniciativa de cada medio. Esto sería lo ideal, para que no lo vean como una amenaza a la libertad de expresión y al trabajo periodístico, sin embargo, como se ha mencionado anteriormente, se necesita mucha madurez de parte de las empresas de comunicaciones para que reconozcan que existe la necesidad de un organismo que las regule, pues siempre han estado a favor de la autorregulación.

Por tanto, respondiendo al último objetivo específico de esta investigación, indagar el perfil idóneo del ombudsman de las audiencias de los medios de comunicación para El Salvador, se construyó una propuesta de perfil, utilizando, además, lo expresado por los entrevistados y participantes de los grupos focales, sumando a la base teórica utilizada una serie de características y funciones que debe tener el defensor de las audiencias en El Salvador.

Se determina que el perfil de la persona que ostente el cargo de ombudsman de las audiencias en los medios de comunicación salvadoreños podría resumirse en los siguientes atributos: ser totalmente independiente, estar comprometido con la población; conocer de periodismo e investigación, y un elevado perfil de credibilidad y no tener afiliación política.

Las personas que participaron en esta investigación no dieron un nombre concreto de quién podría ser el defensor de las audiencias en El Salvador; sin embargo, y como lo plantea Cid (2012), este cargo suele ser ocupado por periodistas de gran prestigio y con bastante experiencia en 
el medio, por lo que pueden servir de ejemplo para el gremio periodístico y, debido a su peso, su trabajo es más influyente al interior de las redacciones, con ello puede promover cambios en la forma de producción de la información que llega a la población.

El Salvador podría retomar ejemplo de países latinoamericanos, en donde los defensores de las audiencias pueden ser parte de las redacciones, ya sea de forma individual o mediante la construcción de un comité que verifique el trabajo periodístico. En la región latinoamericana predomina el nombramiento del defensor a cargo de los directivos de la empresa periodística [sea la junta directiva o el presidente] (Zeta y Herrera, 2004). El Salvador podría incluir a los jefes de redacción y la mesa de editores, así como a la Apes para tener la perspectiva del periodismo y no solamente la empresarial.

Así como lo plantean Zeta y Herrera (2004), el defensor de las audiencias en El Salvadoro puede tener las siguientes funciones: 1. elevar la credibilidad del medio de comunicación, mostrando el cuido de la empresa periodística en la producción de sus contenidos, 2. publicar la actuación realizada para la verificación de los resguardos ético y técnico con los que se publican las informaciones, 3. promover la labor pedagógica de los medios de comunicación para con la población, 4. revisar contenido de los medios informativos relacionados en general, poniendo énfasis en temas sensibles como la niñez, las mujeres, la violencia social, el medio ambiente, la política y 5 . revisar quejas de los lectores, televidentes y oyentes, para darles respuesta y establecer la conexión con la ciudadanía.

Tomando de referencia el entorno salvadoreño de El Salvador, y según las personas participantes en la investigación, el defensor de las audiencias debe ser establecido desde los medios de comunicación con la participación de los directivos, pero también de los periodistas.

\section{Discusión}

Cuando se habla de derecho a la información y libertad de expresión en El Salvador, según los resultados obtenidos, no puede haber una respuesta absoluta. Por un lado, existen las condiciones para que se puedan ejercer ambos derechos; hay diversos medios de comunicación, tanto formales (radios, televisoras y medios impresos) como informales (todos aquellos que surgen del internet: como blogs, Twitter, etc.). Además, en el 2010 se aprobó la Ley de Acceso a la Información Pública, que permitió la creación del Instituto de Acceso a la Información Pública.

Por otro lado, los medios de comunicación salvadoreños están vulnerando, con sus publicaciones, algunos derechos y garantías constitucionales. Uno de ellos es el artículo 2 de la Constitución salvadoreña, el cual garantiza el derecho al honor, a la intimidad personal y familiar y a la propia imagen, ya que dentro de sus contenidos predomina el sensacionalismo, evidenciado en imágenes de cadáveres, rostros sangrantes, exposición de personas detenidas en ruedas de prensa, ignorando así la presunción de inocencia y vulnerando así su honor y reputación.

Otra garantía constitucional que usualmente vulneran los medios de comunicación es el derecho de respuesta, por lo cual en algunos casos extremos los demandantes han tenido que acudir a instancias internacionales para ser retribuidos, pero en las ocasiones en las que sí ha sido otorgado este derecho no se ha hecho según establece la ley, es decir, en iguales condiciones que la publicación original (similar ubicación, tamaño o espacio, programa o en similar horario).

Además del aspecto del derecho de respuesta, otro que también se debe considerar a la hora de evaluar qué tanto se garantiza el derecho a la información y la libertad de expresión es el de que los principales medios de comunicación salvadoreños son empresas que responden a intereses económicos y políticos. Ese es uno de los factores por los cuales ciertos sectores (grupos, asociaciones, etc.) de la población, opuestos a dichos intereses, no tienen espacio para divulgar sus actividades o noticias. En la agenda periodística de los medios se impone su propia línea de opinión, ignorando las necesidades informativas de las audiencias, mientras que estas parecen estar "adormecidas" ante a la realidad que le venden los medios de comunicación.

En consecuencia, los medios de comunicación salvadoreños se muestran renuentes frente a cualquier iniciativa de mejorar la calidad de sus contenidos, tachando dichas iniciativas como atentatorias contra la libertad de expresión y de prensa. Si bien se inclinan a favor de la autorregulación, este concepto queda a discreción de cada empresa mediática; y no existen parámetros para garantizar que en realidad los medios estén aplicando medidas para mejorar sus contenidos. 
En vista de la calidad y el tipo de contenidos que predominan en los medios, la serie de faltas que estos cometen, afectando la credibilidad y el trabajo periodístico y siendo el ombudsman de las audiencias uno de los mecanismos de autorregulación, resulta necesario que haya iniciativas que lleven a la creación y fortalecimiento de esta figura, como un mecanismo que vele porque los contenidos respondan a los intereses de las audiencias; vele porque el trabajo de los medios de comunicación se haga de forma ética y responsable, y sobre todo sea un enlace entre las audiencias olvidadas y las empresas mediáticas.

Zeta y Herrera (2004) establecen que profesionalmente, el ombudsman enfrenta dos amenazas importantes en el ejercicio de su función: la primera es su aceptación al interior de las salas de redacción de los medios de comunicación. La segunda proviene desde los intereses empresariales de los medios de comunicación. Estas dificultades parten de desconocimiento y de prejuicios generados a partir de rumores empresariales y directivos.

Es por ello que en El Salvador hará falta un proceso de información a la ciudadanía y en los medios de comunicación sobre esta figura, colocando sus beneficios en la garantía al derecho de la información y del control de un trabajo periodístico que resguarde adecuadamente elementos técnicos y éticos.

En lo que respecta a la aceptación de las defensorías de las audiencias de los medios de comunicación de los contenidos informativos en grupos sociales, los resultados arrojan una amplia aceptación de esta figura en todos los sectores a excepción de los medios de comunicación.

Todos los sectores consultados coincidieron en la necesidad de esta figura para contribuir a la transparencia y democratización de los medios y mejorar la calidad de las noticias. Por otro lado, no existen impedimentos legales para su funcionamiento, hay reglamentos no vinculantes (como el código de ética de la Apes, entre otros), que mencionen la necesidad de que en los medios de comunicación se habilite un ombudsman de las audiencias como parte de sus mecanismos de autorregulación.

Sin embargo, esta figura en el ambiente salvadoreño ha sido, sin temor a equívoco, muy poco o nada difundida; como consecuencia de ello muy pocas personas tienen conocimiento de sus funciones y del trabajo que realiza en otros países de Latinoamérica.

Concretamente en los medios de comunicación de este país, las defensorías de las audiencias son percibidas como un elemento innecesario, pues, además de considerar que ya cuentan con procesos para garantizar la participación ciudadana, consideran que la labor particular de esta figura ya está siendo desarrollada por el editor del medio; y por tanto estiman que su trabajo cumple con los requerimientos éticos de la labor periodística.

Esta apreciación no es compartida por otros sectores de la sociedad, quienes sí consideran que el ombudsman de las audiencias es necesario para mejorar la calidad del trabajo periodístico y de la información que los medios de comunicación están brindando a la población.

Con todo, la percepción es que los medios de comunicación nunca aceptarían una figura como el ombudsman dada la polarización imperante en el país y el desconocimiento en la mayoría de sectores sobre la labor de este personaje en otros países; pero sobre todo por la naturaleza económica del sistema mediático, que no admite instancias que lo vigilen, que lo monitoreen, que lo señalen, que le sugieran buenas prácticas en el manejo de la información. Tal como afirma Pauwels (2014), con la existencia del defensor de las audiencias los medios asumirían públicamente un compromiso de respeto a principios éticos y de diálogo con sus audiencias.

Asimismo, otro aspecto que influye en la aceptación del ombudsman de las audiencias son las audiencias mismas, que hasta la fecha se han mostrado poco críticas frente a los contenidos que ofrecen los medios. Según los resultados, los medios han acostumbrado a sus audiencias al ofrecerle contenidos que no responden a los intereses del colectivo, sino a los propios intereses económicos e incluso políticos de los propietarios de la empresa mediática.

Finalmente, para que esta figura pueda implementarse en los medios de comunicación salvadoreños, hace falta madurez, por un lado, de los medios de comunicación, para que reconozcan que deben mejorar sus contenidos y en general su trabajo; y por otro, de la sociedad civil, para que tenga conocimiento crítico de su realidad y haga uso de los diferentes mecanismos que el estado de derecho le 
proporciona para hacer valer su derecho a la información y a la libertad de expresión.

De acuerdo con los resultados de las entrevistas y del grupo focal, en El Salvador no es factible la utilización de la defensoría de las audiencias de los medios de comunicación, puesto que no hay disposición por parte de los medios de comunicación.

Pese a ello, en el 2018 el periódico digital ElFaro.net anunció su defensora de las audiencias. Esto abre un punto de estudio para darle seguimiento y reponer a si es factible que se mantenga en el tiempo y en un contexto como el salvadoreño. Esta primera defensoría abre paso a nuevas perspectivas y puntos de análisis.

Si bien los medios no ven a futuro próximo la construcción de una figura como un ombudsman, se visualiza la necesidad de una instancia que regule el contenido que se transmite por los medios de comunicación debido a que hay una percepción generalizada de que mucho de la información y del contenido en general que se publica no va acorde con los verdaderos intereses de la población.

Tanto en los medios de comunicación como en las personas que consumen información existe la necesidad y urgencia de que se verifique lo que la radio, televisión, prensa e internet publican, pero están conscientes de que las estructuras no permitirán esa figura. En ese sentido, el perfil idóneo del ombudsman de las audiencias de los medios de comunicación para El Salvador, según los entrevistados y participantes de los grupos focales, tiene que ser una persona con conocimiento de la dinámica de los medios de comunicación y del periodismo, pero que no esté unido a ningún partido político.

Javier Darío Restrepo (2016), principal impulsador del ombudsmen en América Latina, asegura que el defensor de la audiencia no es una figura cómoda para los medios, pero debe ser vista como impulsadora hacia la excelencia, en donde está inmerso el derecho de las audiencias de recibir información adecuada.

\section{Referencias}

Cid Rodríguez, G. (2012). "El defensor de la audiencia, un enlace entre el público y los medios de comunicación". Recuperado de http://www.lahuelladigital.com/eldefensor-de-la-audiencia-como-enlace-entre-publicoy-medio/
García, C. (2016). La transparencia en la producción de noticias de los medios de comunicación estatales de El Salvador. Santa Ana: Editorial Unasa.

Hernández, R., Fernández, C., \& Baptista, P. (2014). Metodología de la investigación (6.a ed.). México, D. F.: McGraw-Hill Education.

Herrera. S. (2008). "El defensor de la audiencia como instrumento para la educación en medios". Comunicar. 15(30), 127. DOI: 10.3916/c30-2008-02-005

McKenna, K. (1993). "The loneliest job in the newsroom". The American Journalism Review. Recuperado de http://newsombudsmen.org/articles/articles-aboutombudsmen/the-oneliest-job-in-the-newsroom

Naciones Unidas (2015). "Declaración Universal de los Derechos Humanos". Recuperado de http://www. un.org/es/documents/udhr/UDHR_booklet_SP_web.pdf Naciones Unidas-Cepal (2018). "Agenda 2030 y los Objetivos de Desarrollo Sostenible: una oportunidad para América Latina y el Caribe. Objetivos, metas e indicadores mundiales". Recuperado de https://www.cepal.org/es/ publicaciones/40155-agenda-2030-objetivos-desarrollosostenible-oportunidad-america-latina-caribe

ONO (2018). "Building Trust - Tools and Ideas for Ombudsmen, Public Editors and Standards Editors to rebuild public belief in news media". Recuperado de https://www.newsombudsmen.org/2018-conferencebuilding-trust-tools-and-ideas-for-ombudsmen-publiceditors-and-standards-editors-to-rebuild-public-beliefin-news-media/

Pauwels, F. (2014). "Las defensorías de las audiencias en América Latina: Hacia un diálogo crítico y constructivo entre medios y públicos". Recuperado de http:// congreso.pucp.edu.pe/alaic2014/wp-content/ uploads/2013/11/vGT18-Flavia-Pauwels.pdf

Restrepo, J.D. (2016) "El defensor en tiempos de crisis". Recuperado de http://www.fnpi.org/es/etica-segura/ un-defensor-en-tiempos-de-crisis

Salgado L.A. (2007). "Investigación Cualitativa: diseños, evaluación del rigor metodológico y retos". Recuperado de http://pepsic.bvsalud.org/pdf/liberabit/v13n13/ v13n13a09.pdf

Unesco (2014). "Tendencias mundiales en libertad de expresión y desarrollo de los medios: situación regional de América Latina y el Caribe". Recuperado de https:// unesdoc.unesco.org/ark:/48223/pf0000229042

Zeta, R., \& Herrera, S. (2005). "Situación del Ombudsman en América Latina". Sala de Prensa. Recuperado de http:// www.saladeprensa.org/art587.htm 